Dietmar Koch

Universidad de Tubinga

\title{
Pensamientos filosóficos sobre lo divino a partir de Friedrich Georg Jünger y Martin Heidegger ${ }^{(1)}$
}

En Amriswil, el 25 de agosto de 1968, con motivo de los setenta años de Friedrich Georg Jünger, Martin Heidegger ofreció en su honor la conferencia titulada "El poema". En ella se dice lo siguiente:

Hay que soportar la penuria apremiante del decir nombrador de la llegada de los dioses presentes. Hay que portar ese decir "silenciosamente". Pero lo suyo no pertenece al poeta como una posesión adquirida por él mismo. Lo suyo consiste más bien en que el poeta pertenece a aquello para lo cual es requerido. Porque el decir del poeta es requerido para dejar aparecer, mostrando, velando y develando, la llegada de los Dioses. Estos requieren la palabra del poeta para su aparecer, para ser recién ellos mismos en el aparecer $(G, 191)(2)$.

Estas frases pertenecen a una controversia con la obra de Friedrich Hölderlin. No es necesario destacar la enorme significación de la obra de Hölderlin para el pensar de Heidegger ni tampoco su importancia para Friedrich Georg Jünger. El discurso acerca de los "dioses presentes", para los cuales vale la penuria apremiante del poeta, es precisada en la conferencia arriba mencionada. La aclaración tiene lugar a partir de dos versos del himno Germanien, de Hölderlin: “'Dioses huidos! También vosotros, vosotros presentes, antaño verdaderos, tuvisteis vuestros tiempos'. Los presentes, antaño verdaderos, no han desaparecido ni se han extinguido, sino solamente se han ido" (G 184). La posible llegada "de los dioses verdaderamente presentes", para la cual vale la penuria apremiante de Hölderlin en el contexto histórico-occidental del día y la noche de los dioses, no significa, según Heidegger, "de ninguna manera el regreso de los antiguos dioses" (G, 185).

(1) El presente artículo es la reelaboración de la conferencia dictada por el Prof. Koch. el 1 de octubre de 2008, en el coloquio "Hölderlin-Heidegger", organizado por la Universidad Alberto Hurtado (Chile). El artículo fue traducido al castellano por el Prof. Roberto Rubio. La visita del Prof. Koch, así como la traducción del texto, tuvieron lugar en el marco de los Proyectos Fondecyt 11060023 y 7080030.

(2) La versión en español de las diversas citas es una traducción del texto en alemán correspondiente, indicado por el autor mediante siglas o notas al pie. La única excepción es el fragmento de la Ilíada, el cual ha sido tomado de la traducción española editada por Gredos (N. del T.). 
Teniendo en cuenta la modernidad, que se funda en el proyecto de una subjetividad autónoma, a muchos puede parecer extraño que lo divino y los divinos representen una tarea para un pensador del siglo XX -y además decididamente fuera de la diferencia entre fe cristiana y saber filosófico. Hay que hacerse cargo de esa extrañeza. Consideramos aquí la posición fundamental del pensamiento de Heidegger desde la mitad de los años treinta hasta su muerte: una posición que se expresa, dicho de modo muy resumido, en la unidad contraoscilante entre la diferencia de ser y ente-diferencia que se muestra y se asigna- y el Dasein humano singular que co-rresponde a esa diferencia. Esa unidad lleva por nombre Ereignis. El pensar del Ereignis no puede ser captado suficientemente sin la dimensión de lo divino, determinada y aún por determinar mediante el pensamiento. Lo sagrado en tanto dimensión para lo divino -o, en el elevado tono heideggeriano: para la divinidad -, lo divino como la dimensión para los divinos en tanto "mensajeros de la divinidad que hacen señas" (D, 171), es una figura esencial del pensar del Ereignis, la cual retorna constantemente. Esa dimensión de lo divino fue obtenida en una discusión fenomenológico-hermenéutica con el pensar y el poetizar griego temprano, en parte también con los mitos de Platón, así como con la obra de Friedrich Hölderlin. Como ya hemos indicado, en esa discusión no se trata de una restitución del mito griego. Los dioses griegos permanecen como los dioses "sidos". Y, sin embargo, en la discusión con ciertos fenómenos y palabras clave de lo griego se obtiene una determinación fenomenológico-hermenéutica de lo divino que se ha mantenido como paradigmática desde mitad de los años treinta hasta la muerte de Heidegger. No podemos abordar aquí una determinación filosófica exhaustiva de lo divino en la obra de Heidegger. No obstante, hemos de considerar algunos rasgos de su pensar, en la medida en que surgen de la controversia con el pensar y poetizar griego temprano. Ahora bien, no tomaremos el punto de partida para el asunto en discusión desde el pensar heideggeriano, sino desde la obra de Friedrich Georg Jünger.

El derecho a vincular ambos autores en el contexto de la controversia con lo mítico-griego nos lo da un fenómeno al que ambos concibieron como la clave para una presentación que desarrolle lo que un griego de la época greco-temprana y de la época clásica entendía por dios o lo divino. Nos referimos a lo que se expresa en la noción de daimonion y del daimon, o bien de los daimones. Para este concepto de daimonion o bien de daimones -que de ninguna manera hay que comprender con Sócrates como la voz de la conciencia que advierte y rechaza-, tanto Heidegger como Jünger escogen diversas traducciones, las cuales tienen su correspondiente legitimidad. Para nuestro trabajo, la más lograda, por ser la más elocuente, es la de Friedrich Georg Jünger. Ciertamente también ella requiere de una interpretación explicativa, en tanto escoge una expresión latina. Lo griego-divino, el daimonion o el daimon, son para Jünger el "Numen".

Numen es el encuentro, el contacto del hombre con la divinidad. Numen es también la impresión que provoca ese contacto, la cual, como dice Virgilio, se llena de un escalofriante temor reverencial (multo numine suspensus). La divinidad misma es Numen y tiene un Numen, mediante el cual muestra poder, fuerza, voluntad, mandato y altura. El obrar e imperar de los dioses, el envío divino es Numen. Numen es una voz latina. Al Numen latino corresponde el Daimon y Daimonion griegos (GM, 219). 
El Numen en tanto encuentro con el dios o lo divino contiene en el latín "nuere" una indicación sobre el lenguaje de lo divino o del dios. "Nuere" significa saludar, hacer señas, dar una señal. Apropiadamente dice el poema "Rousseau" de Friedrich Hölderlin: “... y señas son / desde antaño el lenguaje de los dioses”. Este hacer señas -es decir: este aparecer indicador repentino que luego nuevamente se retrae- corresponde al griego "semainein" -el indicar o significar que se muestra y se retrae, en el sentido de un mostrar indicador, como lo encontramos en el Fragmento B 93 de Heráclito. Allí se dice sobre Apolo: "El Señor, cuyo Oráculo está en Delfos, no se expresa ni oculta, sino que da un signo (signi-fica)" (3). Este indisponible e instantáneo, indicativo y señalador encuentro con el Numen es para el hombre a la vez determinante y armonizador. Un armonizar y estar determinado, sobre el cual este no dispone. Dicho con Friedrich Georg Jünger: Al Numen le pertenece Nomos. Nomos es aquí la indicación, lo indicativo en cuanto determinante: “¿Cuál es en primer lugar la relación de Numen y Nomos? El Numen incluye en sí íntegramente al Nomos y no lo libera, así que este no puede desprenderse autónomamente como ley, regla, prescripción (...)" (GM, 222) A esto que determina y armoniza, al Numen que indica y hace señas, le copertenece el transformar. Al encuentro con el Numen pertenece que aquel con el cual el Numen se encuentra, devenga otro. Lo divino se experimenta entonces en el encuentro con un Dios, a cuyo nomos le es propio un poder transformador. El fenómeno de la transformación en el contexto de lo divino surge aquí también en otro ámbito esencial. El dios o lo divino -posteriormente volverermos sobre esta diferencia- aparece como Numen que me afecta, que habla y hace señas, en la figura transformada conocida para mí. Dicho con Friedrich Georg Jünger:

En la transformación, el Dios despierta una apariencia; aparece y a la vez parece ser algo que no es. La visibilidad de la transformación nunca es universal. Depende del Dios, quienquiera este que lo perciba. A veces lo ve solamente aquel que participa inmediatamente; en otros casos lo perciben todos los presentes. Se reconoce la transformación cuando se reconoce al Numen (GM, 230 sg.).

Lo divino aparece en la figura de un hombre, por ejemplo de un amigo, en la figura de un animal, de un paisaje, siempre en la figura transformada de algo conocido y familiar para nosotros. Este fenómeno esencial de la transformación nos ocupará luego en un modo más detallado. Pero antes de continuar con la determinación de daimonion o Numen, deberíamos traer a la vista al menos en un ejemplo la presentación poética de un encuentro mítico-griego con lo divino. En nuestro ejemplo, este encuentro con lo divino es el encuentro con el poder armonizador-determinante de la prudencia y la templanza, el encuentro que Aquiles experimenta con la diosa Atenea. El encuentro con lo divino es, en lo griego, una experiencia esencial en tanto experiencia transformadora. El ejemplo del libro I de la Ilíada (Ilíada I 199 sg.) (4) considera la disputa entre Agamenón, jefe de las fuerzas griegas, y Aquiles, su guerrero más destacado. Para ilustrar brevemente la situación, digamos que Aqui-

(3) Cf. Heráclito: Fragmente, ed. por Bruno Snell. Munich: Heimeran, 1989.

(4) Homero: Ilíada, trad. de E. Crespo. Madrid: Gredos, 1982, pp. 7sg. 
les fue provocado hasta el extremo por el discurso anterior de Agamenón, lo cual encendió en él una ira irrefrenable.

Así habló, y la aflicción invadió al Pélida, y su corazón dentro del velludo pecho vacilaba entre dos decisiones: o desenvainar la aguda espada que pendía a lo largo del muslo y hacer levantarse a los demás y despojar él al Átrida, o apaciguar su cólera y contener su furor.

Mientras revolvía estas dudas en la mente y en el ánimo y sacaba de la vaina la gran espada, llegó Atenea del cielo; por delante la había enviado Hera, la diosa de blancos brazos, que en su ánimo amaba y se cuidaba de ambos por igual. Se detuvo detrás y cogió de la rubia cabellera al Pélida, a él solo apareciéndose. De los demás nadie la veía.

Quedó estupefacto Aquiles, giró y al punto reconoció a Palas Atenea; terribles sus dos ojos refulgían. Y dirigiéndose a ella, pronunció estas aladas palabras: “¿A qué vienes ahora, vástago de Zeus, portador de la égida? ¿Acaso a ver el ultraje del Átrida Agamenón?

Mas te voy a decir algo, y eso espero que se cumplirá: por sus agravios pronto va a perder la vida". Díjole, a su vez, Atenea, la ojizarca diosa: "Para apaciguar tu furia, si obedeces, he venido del cielo, y por delante me ha enviado Hera, la diosa de blancos brazos, que en su ánimo ama y se cuida de ambos por igual.

Ea, cesa la disputa y no desenvaines la espada con tu brazo. Mas sí, injúrialo de palabra e indícale lo que sucederá. Pues lo siguiente te voy a decir, y eso quedará cumplido: un día te ofrecerá el triple de tantos espléndidos regalos a causa de este ultraje: tú domínate y haznos caso".

En respuesta le dijo Aquiles, el de los pies ligeros:

"Preciso es, oh diosa, observar la palabra de vosotras dos, aunque estoy muy irritado en mi ánimo, pues así es mejor.

Al que les obedece, los dioses le oyen de buen grado".

Dijo, y sobre la argéntea empuñadura puso la pesada mano.

En la vaina empujó de nuevo la enorme espada y no desacató La palabra de Atenea. Y esta marchó al Olimpo, a la morada de Zeus, portador de la égida, junto a las demás deidades.

Posteriormente retomaremos este ejemplo.

Una de las mejores presentaciones de las figuras esenciales griegas acerca de lo divino se encuentra sin duda en la obra de Friedrich Georg Jünger Mitos griegos, debido a su precisión y, dicho con Nietzsche, a su "fuerza plástica", de igual calidad al desarrollo que encontramos en el renombrado libro de Walter Otto Los dioses de Grecia. Mitos griegos es una obra de la cual dijo su hermano Ernst Jünger en una entrevista a mediados de los años noventa: "De las numerosas obras 
que él escribió, considero a Mitos griegos como el texto más significativo, y al que más estimo" (5).

Se puede suponer que en Mitos griegos se trata de una exposición de figuras esenciales históricamente ya pasadas. Y Friedrich Georg Jünger no estaría básicamente en contra de ello. Y, sin embargo, se dice más que esto en ese libro, así como en los desarrollos de Jünger para el cumpleaños número cien de Walter Otto en 1974.

Consideremos las siguientes expresiones de Jünger:

Si el lenguaje es convertido en un cálculo, entonces el camino para ello consiste en que lo lingüístico es alejado del lenguaje de un modo calculante. Hay que reconocer también que el lenguaje, en el ámbito mítico, no está inicialmente al servicio del entendimiento y de la comunicación, sino que está ahí por el testimonio y la transformación. Pero el lenguaje solo puede transformar en la medida en que incluya al Numen, porque de otro modo esto no resultaría (GM, 236).

Como complemento de esto, afirma Jünger:

El hecho de que en nuestro sistema científico las ciencias exactas y las ciencias del espíritu se separen y amenacen absorberse recíprocamente, se explica porque no está más presente un Numen, porque se ha perdido también la fuerza de la transformación por el lenguaje. Solamente los poetas vislumbran esto, a estos está ligado por ello el destino del lenguaje. Un lenguaje sin Numen está muerto (GM, 237).

La presencia del Numen en el lenguaje, y no solo en el lenguaje poético, parece ser esencial para una comprensión no reductiva de la totalidad y la realidad: esta es una idea que se extiende más allá del texto Mitos griegos e indica la peculiar autocomprensión poética de Friedrich Georg Jünger. Traer a lenguaje al Numen es, en el fondo, la cuestión de la obra poética. En la controversia con el mito griego se obtiene algo que no se agota con aquél, sino que tiene una significación fundamental y debe ser nuevamente determinado una y otra vez. El Numen o daimonion ha recibido en lo mítico-griego una impronta histórica, que también para Friedrich Georg Jünger es una impronta ya acontecida. Pero en tanto que acontecida ella, en una figura transformada, está dada de vez en vez como tarea para el presente y futuro de lo poético. El Numen es comprendido aquí en un sentido estricto, en sentido griego, y esto significa: está concebido como la medida de lo poético sin más.

Regresemos a la exposición sobre el Numen o el daimonion. Nos interesan aquí los planteamientos y rasgos fundamentales de una fenomenología hermenéutica de lo sagrado a partir del Numen o del daimonion como la determinación clave del fenómeno.

Preguntemos otra vez y desde el principio y retomemos la extrañeza mencionada al comienzo, extrañeza relacionada con el recurso filosófico a lo divino en la obra de Heidegger. Este recurso filosófico se encuentra fuera del contexto teológico-cristiano, en el cual la filosofía, durante largo tiempo, tuvo su único lugar para la controversia

(5) Gnoli, A. y Volpi, F.: Ernst Jünger. Die kommenden Titanen. Viena - Leipzig: Karolinger, 2002, p. 58 . 
con lo divino. En el marco de nuestra tarea, tomemos el punto de partida a partir de las líneas evocativas de Friedrich Georg Jünger respecto a Walter Otto:

Lo divino -dice Jünger citando a Otto- solo puede ser experimentado. Experiencia significa que los dioses no pueden ser inventados o pensados o representados. Pero ¿en qué experiencia está presente lo divino? No cualquier discurso basta para ello. En tal experiencia está ya el dirigirse, sin el cual no hay nada que venga al encuentro. (...) Las musas se aproximan a los hombres musicales, la Hora se acerca solamente a quien sigue su curso y su imperar a través del año, y las Gracias obsequian solamente a quien puede ingresar en su danza. Así, en todos los tiempos, solamente el hombre que vive poéticamente ha tenido un camino y acceso hacia ellas. Sin el ritmo, cuyo origen divino conocían los griegos, sin su movimiento, que es festivo, todo permanece mudo. Sin el ritmo no hay fiesta, sin él decae toda festividad (TH, 2).

Retomemos el inicio de esta cita -“la experiencia de lo divino"- y acerquémonos al fenómeno esencial que está en discusión desde los posibles reversos de lo divino, es decir, desde las huellas de su esencia, como también del lado de su contraesencia. La huella y la contraesencia deben trazar un puente para una discusión acerca del Numen y del daimonion, tal como aparecen en la obra de Heidegger. En ella volveremos a encontrar lo que ya hemos dicho acerca de Numen y daimonion. La experiencia de lo sagrado es un experienciar. ¿Dónde nos salen al encuentro, tanto en nuestro uso del lenguaje como también en nuestro Dasein cotidiano, las huellas de ese experienciar? Por ejemplo, allí donde determinamos como "logrado por encima de la medida" algo especialmente elevado e insuperable con lo que nos encontramos, es decir, algo respecto a lo cual con asombro nos vemos expuestos, algo extraordinariamente bello, a lo cual, en un dejo de exaltación y entusiasmo, llamamos "divino". Por otra parte, nos encontramos con lo divino como contraesencia, por ejemplo, cuando decimos, respecto a un hombre que dedica su vida apasionadamente a ganar dinero y no conoce otra cosa que aumentar el dinero, que para él "el dinero es el dios" al cual ofrece su vida, pensamiento y acción. Incluso cuando el dinero no sea propiamente un "dios", sino un falso dios, un ídolo, al cual se sirve y por el cual se sacrifica todo el tiempo, este servir al ídolo nos indica un camino, más bien un desvío para una fenomenología hermenéutica de lo divino. Si lo divino no fuera una determinación fundamental del Da-sein, no podría haber entonces transformaciones históricas ni tampoco distancia de lo divino, es decir, retraimiento. Lo divino -incluso en la figura de la contraesencia, o sea, de las inversiones y reducciones- es lo dominante, lo más elevado y lo más extremo, lo que nos determina en nuestro Da-sein, templándonos. Es algo hacia lo que tendemos, que nos cautiva, nos quita el aliento, que vale para nuestra pasión y nuestra vida, nuestro obrar y actuar, algo que para nosotros es sagrado, intocable, algo cuya elevación nos estremece desde el fondo. Si no somos completamente indiferentes respecto a lo que nos viene al encuentro, conocemos tales experiencias de determinante cercanía, aun cuando no estemos habituados a vincularlas con lo divino, y esto significa aquí: con lo extremo y más bello. Lo divino es lo más elevado y bello, es la fiesta del Dasein. 
$\mathrm{Si}$ a este ejemplo de lo divino, referido a la contraesencia, lo despojamos de su aspecto negativo, entonces aparecen determinaciones características de un modo de comprensión de lo divino que es griego, pero que a la vez se abre fenomenalmente: lo divino es areté de algo, es decir, la figura plena y a la vez el poder que puede producir la figura perfecta. Ningún artesano griego, ningún technítes que no esté determinado por el poder de la prudencia y la templanza, puede construir un barco y menos aún uno perfecto, ante el cual estemos de pie maravillados. El artesano necesita de la ayuda del poder, en griego dynamis, también nombrado con el nombre de Atenea. El vencedor de la competencia olímpica honra a las fuerzas indisponibles, sin las cuales su victoria en ese día y en ese instante no hubiera sido posible. Para los atletas, la victoria en la competencia olímpica es akmé, el florecer de su existencia. Areté y akmé son a la vez la medida, to metrón, al cual pertenece el pensar y el obrar. El metrón es lo dominante, el arché. Según la concepción griega, el atleta, en cuanto vencedor, no es ningún dios, sino un semidiós, así como el poeta Píndaro, quien en logrados versos canta tal victoria, es también un semidiós, gracias al favor y la honra de las Musas y las Gracias. Sin el encuentro indisponible y el donado acceso al poder de lo musical no hay ningún poema logrado. El querer tiene aquí límites frente al resultar o lograrse algo; algo más debe añadirse y sobre todo debe preceder. Todo querer se funda en lo querido, en algo que se ha mostrado como aquello por querer. El querer algo se funda -al modo del estar interpelado y atraído- en el mostrarse. Con este fenómeno del mostrarse estamos expresamente, dicho en griego, en la aletheia, en el desocultamiento. En tanto esencia que piensa y obra, nos encontramos en el desocultamiento de lo que se muestra, nos encontramos interpelados, afectados así y asá, y correspondemos a eso que se muestra de diversa manera. Obviamente, no todo lo que se muestra es de tal modo que nos transforme y atraiga hacia sí. Y, sin embargo: el lugar y el sitio de la experiencia de lo divino es el desocultamiento. Lo divino es lo más elevado, extremo y poderoso de todo posible mostrarse, es lo más bello del desocultamiento y en su contraesencia lo más feo, lo peor, lo antidivino. Lo divino pertenece al desocultamiento y a la fuente de este, el ocultamiento. Conocemos el juego mutuo entre desencubrimiento y encubrimiento ya desde la cita de Heráclito y desde el fenómeno de la seña: el hablar que muestra y a la vez oculta. En la comprensión griega temprana, junto con la dimensión de la aletheia, del desocultamiento, está puesta aquella dimensión llamada physis, es decir, el emerger -apareciendo- de todo lo que es.

Aquello que nos hace señas, o sea, que nos determina templando a fondo, en la medida en que estemos transformados en relación a lo que nos sale al encuentro, es el Numen, el daimonion. Nosotros no podemos producir esta transformación, como tampoco el encuentro mismo. Ninguna de ambas cosas está en el poder de nuestro querer o de nuestra disponibilidad. Sin esta determinación del encuentro indisponible, transformador, con lo que se muestra, lo divino permanece captado de manera insuficiente en esta interpretación que se puede experimentar fenomenalmente. Junto con esto hay que pensar, como ya hemos dicho, que a toda esencia corresponde su contraesencia, a todo lo divino lo antidivino, a los dioses pertenecen contradioses e ídolos o dioses falsos. Toda esencia, también la esencia de lo divino, está siempre codeterminada por una disputa que le pertenece. Tal disputa es incluso uno de los indicios de la historicidad de lo divino en el sentido del "no más" y del "aún no" de la llegada oculta de la "inagotable esencia" de lo divino (N, 177). 
Heidegger considera este aparecer que sale al encuentro, este mostrarse de lo divino, en la célebre Lección sobre Parménides del semestre de invierno de 1942/43. Allí lo considera como un aspecto que viene al encuentro, como un aspecto que aparece, el cual es traído a lenguaje en la mirada percipiente o captadora del hombre, del Dasein singular. El aspecto de lo divino es, considerado con precisión, el aspecto más resplandeciente, el aspecto más elevado posible de algo, el aspecto más armonizador y determinante de lo que se muestra en el desocultamiento. Nuestra mirada es siempre un mirar que capta, un percibir captador de los aspectos que vienen al encuentro, captador de lo que se muestra apareciendo. Este indisponible juego mutuo entre el aspecto divino que sale al encuentro y la captadora mirada del singular ocurre repentina e instantáneamente -exaiphnes- resplandeciendo y ocultándose, haciendo señas. La seña es, como hemos visto, a la vez una indicación. Esta es un recoger, un reunir la mirada que capta con respecto al aspecto que viene al encuentro. La epifanía -el aparecer divino, el resplandecer de lo divino en sentido literal-, el silencioso, insonoro, instantáneo lenguaje de lo divino y nuestro poético o pensante corresponder son momentos constitutivos del desocultamiento, al cual pertenece tanto lo divino como también lo humano.

En la conceptualidad de Heidegger, el mostrarse del daimonion es el mostrarse de lo extraordinario:

Podemos llamar al daimonion lo extraordinario, debido a que y en la medida en que circunda por todas partes a lo ordinario y se presenta por todas partes en lo ordinario, sin ser, empero, lo ordinario. Lo extraordinario comprendido de esta forma no es, con respecto a lo ordinario, la excepción, sino lo "más natural", en el sentido de la "naturaleza", es decir, la physis, como fue pensada por los griegos. Lo extraordinario es aquello a partir de lo cual emerge todo lo ordinario, aquello de lo cual pende todo lo ordinario sin vislumbrarlo mayormente, aquello en lo cual recae todo lo ordinario. To daimonion es la esencia y el fundamento esencial de lo extraordinario. Es lo que se expone en lo ordinario y esencia inmerso en él. (...) No son "demonios" concebidos como espíritus malignos que revolotean alrededor, sino que determinan de manera anticipada lo ordinario, sin proceder nunca de lo ordinario mismo. Ellos hacen señas en lo ordinario y lo muestran. To daimonion: lo que se muestra indicando en lo ordinario y por tanto, lo que en cierto modo se esencia por todas partes al igual que lo ordinario, aunque nunca sea, sin embargo, algo meramente ordinario ( $\mathrm{P}$, $150 \mathrm{sg}$.).

Para entender este juego recíproco de lo extraordinario y lo ordinario en lo que se muestra - pues también lo ordinario, es decir lo familiar, conocido y habitual, pertenece a lo que se muestra- es decisivo dejar de lado la idea de lo "enorme, imponente, exagerado, extraño" $(\mathrm{P}, 156)$. Lo extraordinario es:

en esencia lo no-llamativo, simple, inaparente, lo cual resplandece, sin embargo, en todo ente. Si concebimos lo extraordinario como lo simple que resplandece en lo ordinario y que no procede de lo ordinario, pero que, no obstante, aparece de antemano en todo lo ordinario, resplandeciendo a través 
y en torno de lo ordinario, entonces es claro que la palabra "extraordinario", en general, empleada aquí, no tiene nada en común con su significado corriente para nosotros, de acuerdo con el cual pensamos siempre algo "impresionante" y "afectivo". En el presente contexto, lo extraordinario que tiene que ser pensado no tiene la huella de lo "monstruoso", a lo que alude también la palabra $(\mathrm{P}, 156)$.

Algunas veces Heidegger determina conceptualmente la diferencia entre lo extraordinario y lo ordinario como la diferencia entre lo inhabitual y lo habitual. "Lo inhabitual aparece. Su aparecer no necesita de un enorme despliegue de lo raro ni del estímulo de lo extravagante. Festejar es liberarse de lo habitual deshabitado mediante el liberarse para lo inhabitual (...) (A, 75) El siguiente pasaje es decisivo: "Lo inhabitual se concentra en que en general hay ente y no más bien nada" (A, 75) Lo inhabitual y extraordinario descansa en lo simple: que el ente en general sea, es ya algo digno de asombro. Lo inhabitual descansa también en que y cómo eso simple, en tanto desoculto, es. Esto aparentemente obvio es para Heidegger el lugar de reunión de lo asombroso y extraño en sentido elevado.

Permítanme, a fin de despejar el malentendido de que lo extraordinario sería lo monstruoso y raro, volver con Heidegger sobre otro malentendido usual respecto a lo divino-griego.

Los griegos, afirma Heidegger, ni han formado a los dioses según figura humana ni han divinizado al hombre. La esencia de los dioses griegos no se puede explicar como un "antropomorfismo", así como tampoco se puede pensar como "teomorfismo" la esencia del hombre griego. Los griegos no han humanizado a los dioses ni divinizado al hombre, más bien han experimentado a dioses y hombres en su diversa esencia y su interacción a partir de la esencia del ser en el sentido del emerger que se descubre, es decir, del mirar e indicar. Por ello justamente los griegos tienen un claro conocimiento de la esencia de los "semidioses", hemitheoi, que esencian en el Entre, entre los dioses y los hombres (P, $162 \mathrm{sg}$.).

En este contexto hay que diferenciar entre la experiencia esencial de lo divino y la presentación poética. La figura que el daimonion puede y debe adoptar en las apariencias de los daimones particulares son, recordemos, siempre figuras transformadas de lo conocido por nosotros en lo ordinario. De allí que el daimon y los daimones, en tanto apariencia del daimonion, pueda adoptar la figura de un hombre, de un animal, un paisaje y también una constelación del cielo. Lo extraordinario aparece siempre en aspectos transformados de lo ordinario. Lo divino se presenta siempre solamente mediante la multiplicidad de lo ordinario, de manera mediata. El daimonion es el lado dirigido hacia nosotros, el lado que aparece de lo divino, que juega hacia nosotros entre cercanía y distancia. O dicho con Platón en el diálogo Symposion (203 a): "Porque dios no se acerca inmediatamente al hombre, sino que a través de la mediación de lo demoníaco (daimonion) se cumple todo trato y diálogo de los dioses con los hombres, tanto en la vigilia como en el sueño. Y quien sea sabio en estas cosas, es un hombre demoníaco; quien, en cambio, tiene conocimiento 
en alguna otra cosa, por ejemplo en un arte inferior o en una artesanía, es un hombre vulgar (bánausos)" (6). Volviendo a nuestro ejemplo de Atenea en la Ilíada: La fuerza armonizadora-determinante del ser prudente y templado, que Aquiles toma y que es presentada poéticamente en la mirada dicente de una figura humana, es solamente indicación de que todo lo extraordinario aparece como ordinario en la figura transformada de lo conocido y familiar, de lo ordinario. En nuestro ejemplo, el instante decisivo estaba en la mirada captadora de Aquiles frente al aspecto de la templanza y la prudencia que salió a su encuentro, el cual tomó a Aquiles y lo determinó en su situación. Ahora bien, ese aspecto pudo determinar porque tuvo el poder de cambiar el temple de Aquiles. Es decisivo que el aspecto de lo extraordinario tiene el poder de cambiar el temple y entonces también de armonizar y templar a fondo. Según Heidegger, los daimones, en tanto apariciones del daimonion, "determinan cada temple anímico esencial, desde el temor reverencial y la alegría hasta la tristeza y el horror. Aquí, por supuesto, estos temples anímicos no tienen que ser interpretados como "estados anímicos" en el sentido subjetivo moderno, sino que deben pensarse más inicialmente como modos del estar templado en los cuales la voz insonora de la palabra templa la esencia del hombre en su relación con el ser" (P, 157). Lo extraordinario aparece en los daimones singulares, se muestra en los modos esenciales del ser que determinan y templan a fondo, modos esenciales que se muestran en lo desoculto al captar percipiente y que pueden ser traídos al lenguaje tanto poéticamente como de manera pensante.

Si bien pensamos la esencia de los dioses griegos más inicialmente cuando los llamamos los que armonizan, podemos nombrarlos así porque pudor y favor y esplendor de la suavidad pertenecen al ser, y estos son experimentados poéticamente en aídos y cháris y de manera pensante en thaumastón y daimónion. De este lucir que armoniza e indica procede el esplendor del théion, el resplandecer. Ahora bien, tal esplendor aseguró a los griegos al mismo tiempo una experiencia de lo oscuro y vacío y del bostezo de apertura $(\mathrm{P}, 164)$.

El theion, lo divino, es el resplandecer más elevado posible, a partir del cual los daimones se muestran, es decir, hacen su arribo en la transformación del ente ordinario: aspecto divino y una contramirada que capta. Los divinos, los aspectos singulares de lo extraordinario, aparecen a partir de lo divino, de lo divinal. En la modificada posición fundamental del pensar heideggeriano, es decir, a partir del "desocultamiento pensado inicialmente" -y esto es el claro abisal de lo autoocultante- los dioses son los "mensajeros" de lo divino "que hacen señas", "los mensajeros de la divinidad que hacen señas" (D, 171)

Digámoslo una vez mas: Los dioses griegos son dioses ya acontecidos -y esto significa: irrepetibles- de la aletheia, del desocultamiento pensado al modo griego, y de la physis, del resplandeciente emerger en el desocultamiento. A partir de la posición fundamental modificada, a partir de la transformación de la aletheia griega en "el claro abisal de lo autoocultante", se puede asegurar a esto divino un

(6) Platón: Das Trinkgelage. Fráncfort: Insel, 1985. 
lugar, ahora transformado pero siempre afín, para su aparecer a la vez transformado. En qué configuración e impronta lo divino, lo divinal, pueda mostrarse en este lugar histórico-modificado, es algo que queda abierto en el pensar de Heidegger y librado a la historia del "claro abisal del autoocultamiento". Lo divinal y lo divino son para Heidegger, a partir del "temple primordial del acontecer de la belleza" (S, 11), modos esenciales, armonizadores e indicativos, del ser abisal-iluminado, respecto al cual se reúnen los respectos fundamentales del ser, es decir, del mundo. Los divinos son los "mensajeros" de lo divino "que hacen señas". En estos "mensajeros que hacen señas" se entrega a sí mismo lo divino, y esto en la llegada instantánea, veladora-develadora, esto es, en el desencubrimiento de lo extraordinario en la transformación de lo ordinario. Los divinos son los "armonizadores" (P, 164), son los que templan armónicamente los "temples fundamentales" $(\mathrm{S}, 9)$. Los temples fundamentales son desarrollos del "temple primordial en tanto intimidad de júbilo y horror". Para Heidegger, el temple primordial es "el fundamento esencial de la belleza" ( $\mathrm{S}, 10)$ Los divinos son los que templan armónicamente los temples fundamentales, a los cuales domina el ser, el ser entendido como Ereignis. El temple primordial y los temples fundamentales son comprensibles apropiadamente, según el planteo heideggeriano, solamente a partir del contragiro del ser mismo, es decir, de la unidad de ser y no-ser en el ser mismo. Aquí solo podemos dar la siguiente indicación: La comprensión de la plena esencia del "temple primordial" como "fundamento esencial de la belleza" necesita de una determinada comprensión del juego mutuo de ser y no-ser en el claro de lo ocultante, comprensión que aquí no hemos desarrollado. En este no-ser está incorporado lo que Heidegger ha llamado el retraimiento histórico del ser, es decir, el olvido del ser junto con el abandono del ser del ente.

Si lo divino y los divinos pertenecen al desocultamiento del primer inicio, del inicio griego temprano, entonces pertenece al desocultamiento modificado en la figura del "claro abisal de lo autoocultante" un aparecer transformado de lo divino conforme a la diferencia e identidad del desocultamiento y el "claro abisal de lo autoocultante". Un momento de lo divino en ese claro es el estado de cosas, según el cual el traer a lenguaje poética y pensativamente lo extraordinario deja a este aparecer como él mismo, es decir, propia e íntegramente. No solo el lenguaje necesita, para decirlo con Friedrich Georg Jünger, del Numen para ser lenguaje. También el Numen, lo extraordinario, requiere al lenguaje, al nombrar pronunciando, para estar ahí como él mismo, íntegramente. La poesía es para Heidegger "el nombrar instituyente de los dioses y de la esencia de las cosas. Habitar "poéticamente" significa: estar en la presencia de los dioses y estar afectado por la cercanía esencial de las cosas" (HWD, 42). O, para volver a nuestra cita del comienzo: "El decir del poeta es requerido para dejar aparecer, mostrando, velando y develando, la llegada de los Dioses. Estos requieren la palabra del poeta para su aparecer, para ser recién ellos mismos en el aparecer" (G, 191).

Démosle, para concluir, la palabra a un poeta, que ha escrito un breve texto en prosa, sin título, que dice a su modo mucho de lo que aquí hemos presentado. El texto se encuentra en las ediciones correspondientes bajo la indicación de sus palabras iniciales "Tenemos una aparición”. Escuchemos, pues, para concluir, algunas palabras de Rainer Maria Rilke sobre la cuestión: 
Tenemos una aparición -y algunos la han invocado; pero ella no retrocede y avanza a través de nuestros muros y no responde. Porque vosotros hacéis como si la conocierais. Pero elevad vuestros ojos y no la conocéis; haced un hueco en torno a ella con el inquirir de vuestras miradas; la matáis de hambre con vuestra ignorancia! Y de pronto, sin angustia, lo extra-ordinario os gritará su nombre y descenderá (7).

\section{SIGLAS}

A Heidegger, M.: Hölderlins Hymne, Andenken. Fráncfort: Klostermann, 1982.

D Heidegger, M.: "Das Ding", en: Heidegger, M.: Vorträge und Aufsätze. Pfullingen: Neske, 1978.

G Martin Heidegger: "Das Gedicht", en: Heidegger, M.: Erläuterungen zu Hölderlins Dichtung. Frankfurt a. M. 1981.

GM Jünger, F. G.: Griechische Mythen. Francfort: Klostermann, 1957.

HWD Heidegger, M.: "Hölderlin und das Wesen der Dichtung", en: Heidegger, M.: Erläuterungen zu Hölderlins Dichtung. Francfort: Klostermann, 1971.

N Heidegger, M: "Nachwort (Ein Brief an einen jungen Studenten)", en: Heidegger, M.: Vorträge und Aufsätze. Pfullingen: Neske, 1978.

P Heidegger, M.: Parmenides. Francfort: Klostermann, 1982.

S Heidegger, M.: "Das Sein (Ereignis)", en: Heidegger-Studien, vol. 15, 1999.

TH Jünger, F.G.: Zum hundersten Geburtstag von Walter Friedrich Otto (22. 6. 1974), en: Otto, W.F.: Theophania. Francfort: Klostermann, 1975.

\section{RESUMEN}

Tanto Friedrich Georg Jünger como Martin Heidegger subrayan, en sus consideraciones sobre lo divino, la figura del daimonion. El presente trabajo saca a la luz algunos aspectos centrales de esa convergencia. En particular, se destaca el acento puesto por ambos en la experiencia daimónica como transformación del mundo ordinario y en el rol decisivo de la palabra poética en dicha experiencia.

Palabras clave: Heidegger, F.G. Jünger, lo divino, daimonion, poesía.

\section{ABSTRACT}

Both Friedrich Georg Jünger and Martin Heidegger, in their considerations of the divine, highlight the figure of the daimonion. The present work brings to light certain central aspects of this convergence. In particular, it highlights the accent placed by both authors on the diamónica experience as transformation of the ordinary world and the decisive role of the poetic word in this experience.

Key words: Heidegger, F. G. Jünger, the divine, daimonion, poetry.

(7) Rilke, R. M.: Werke. Fráncfort: Insel, 1996, tomo 2, p. 122. 